\title{
Synthesis, Characterisation, and Mesomorphic Properties of Some Novel Dicyanoheteropentacenes
}

\author{
L. K. Hiscock, L. N. Dawe, K. E. Maly \\ Wilfrid Laurier University, Waterloo, ON, Canada
}

The synthesis of novel materials for organic electronics is a growing field with potential end applications in energy storage, energy harvesting, displays, and more. Probing the characteristics and properties of novel aromatic and heteroaromatic structures, which increasingly appear in these devices, is a worthwhile pursuit in which we gain insight into the structure-function relationship of previously unknown substances. This in turn allows for more precise tuning of properties for future materials. In certain cases the intermolecular interactions can lead to interesting (and useful) properties such as aggregation-enhanced emission (AIE). Utilizing new materials in novel applications, however, requires a full understanding of their chemical behavior and characteristics.

We report the synthesis of a series of dicyanoheteropentacenes 1-4 incorporating oxygen and/or nitrogen into the linear polycyclic core. These compounds display intense luminescence in solution and the solid state. Compound $\mathbf{4}$, bearing long alkoxy chains, displays a columnar liquid crystalline phase, as shown by differential scanning calorimetry (DSC), polarized optical microscopy (POM), and single-crystal X-ray diffraction. The synthesis, photophysical, mesomorphic properties, and the solid state organization of these compounds will be described.<smiles>N#Cc1c2oc3ccccc3oc2c(C#N)c2oc3ccccc3oc12</smiles>

1<smiles>[R]n1c2ccccc2oc2c(C#N)c3oc4ccccc4oc3c(C#N)c21</smiles>

2<smiles>[R]n1c2ccccc2oc2c(C#N)c3c(oc4ccccc4n3[R])c(C#N)c21</smiles>

3<smiles>[R]Oc1ccc(-c2cc3oc4c(C)c5oc6cc(-c7ccc([R])c([R])c7)c(-c7ccc([R])c([R])c7)cc6oc5c(C#N)c4oc3cc2-c2ccc([R2])c(O)c2)cc1[R]</smiles> 